\title{
MANAGING ARTIFICIAL INTELLIGENCE AS A DRIVER FOR FUTURE TOURISM
}

\author{
Andreea Valentina BUŞILA $\breve{A}^{a *}$, Nicoleta CRISTACHE ${ }^{b}$ \\ ${ }^{a, b}$ Dunarea de Jos University of Galati, Romania
}

\begin{abstract}
The present paper aims to emphasize how Artificial Intelligence can be managed in tourism industry in order to create a positive impact. Although everyone tends to believe that Artificial Intelligence is only about robots taking over the world, the purpose of this article is to come up with powerful meanings of the cognitive computing benefits. For instance, Artificial Intelligence encompasses a lot of different types of capabilities which can give us a better information to run the tourism businesses, but also to improve the customer's experience. To make this study much more significant, we conducted a content analysis based on literature review, within Leximancer computer software, which shows us the most important themes and concepts related to Artificial Intelligence in future tourism.
\end{abstract}

KEYWORDS: artificial intelligence, chatbots, COVID-19, customer experience, robotics, technologies, tourism

DOI: 10.24818/IMC/2021/05.08

\section{INTRODUCTION}

The artificial intelligence "phenomenon" is defined as the development of computer systems able to perform task normally requiring human intelligence, such as visual perception, speech recognition, decision-making, and translation between languages (Oxford Dictionary). Research into artificial intelligence is relatively early on, as well as the phenomenon that is not fully developed. Artificial intelligence is really promising so many alternative solutions for different business issues, however, despite all the abilities regarded to problem-solving and advanced cognitive computing, we can hardly find academic research in this field, especially within tourism industry (Gajdošík \& Marciš, 2019) (Zlatanov \& Popesku, 2019)

The term "artificial intelligence" applies when machines imitate some cognitive functions that are specific to human beings such as: learning, solving the problem, setting some goals, finding the most effective ways of achieving the goals, determining the mechanisms of achieving the goals and anticipating the costs of these activities. In fact, currently, artificial intelligence is an algorithm - an explicit set of instructions the computer follows, which lies in three major technological forces: the first, the exponential increase in computer processing capacity, known as Moore's Law (the number of transistors in dense integrated circuits is doubled every two years), the second - explosive increase in the amount of data accessible to the extent that the information becomes digitized, the third - cloud computing (Polson \& Scott, 2018). Thus, the question arises: are these new ideas "a gate" to a better future of mankind with a greater impact, or are they "an existential danger" to humanity?

\footnotetext{
* Corresponding author. E-mail address: andreea.busila@ugal.ro
} 
While the population is fascinated by robotics, the incorporation of artificial intelligence into the economy has grown faster than ever, especially in the past few years. Technologies have increased their effectiveness, penetrating the economy in various performant ways.

For decades, artificial intelligence and all the new technologies related to it have been widely used in manufacturing industry; however, the service industries have been also experiencing a massive incursion to this regard, changing the way that even travel companies do business or interact with other businesses to improve the efficiency and the customer experience. The Information and Communication Technology was the key for a new beginning of taking into consideration artificial intelligence as the following stage for tourism industry (Kazak et al., 2020). As it is said, to transform some industry, you must really know it from a perspective that considers all the challenges a business has to face. That is what artificial intelligence does, sensing the whole external information, understanding it, then acting for achieving goals and learning from past experiences (Ferràs et al., 2020).

Since tourism industry has always been an early adopter of technology, it has received artificial intelligence with enthusiasm, gradually making its way in a manner of reducing manual practice and simplifying marketing processes. In early 1990s, the whole research within tourism industry was made by using artificial intelligence to analyze hotel occupancy and demand (Law, 2000). Afterwards, the industry started to use all of these technologies for many reasons, such as businesses (Casteleiro-Roca et al., 2018), improving personalization through chatbots and biometric identification (González-Rodríguez et al., 2020), adapting customer proposals (Zheng et al., 2020), considering internet communities (Kirilenko et al., 2018; Topal \& Uçar, 2018), and ensuring rapid response times even when staff members are not there, meaning that artificial intelligence main objective is to facilitate the travel experience and to consolidate the quality of the service engagement. In a world where all the ongoing events represents dramatical changes for tourism industry, it is clearer day by day that new technologies are a powerful driver for future travelers who must understand that artificial intelligence is not just one thing - robots, but it is several things such as revolutionary changes on the tourism scene. This point of view seeks to provide complete knowledge of the different technologies in terms of their function, meanings, demands and expected possibilities in the tourism sector.

Although artificial intelligence is a contemporary topic, there is not an enough approach on the use of new technologies in the tourism industry, but there are companies which did this, such as Trip Advisor, Tata Consulting Services, etc. (Viglia et al., 2014). They exposed outstanding information which is beneficial for travel agencies and for tourism, in general. A survey by Tata Consulting Services (TCS) also found that $85 \%$ of tourism and hospitality businesses use new technologies, and by that, there could be a fast increase in digital mainframe, forecasting over 900 billion dollars at the end of 2021. Google Travel \& Trip Advisor has highlighted 74\% of customers who plan their travel trips using the internet, where more than $45 \%$ of customers plan to use their smartphones (Anurag, 2018).

Among all the studies in the past few years, the outcome shows the habits of customers toward new technologies. This discovery would drive the marketing to assimilate the artificial intelligence in a way of mutual technologies to provide an increased experience for the customers, and they not only suggest a customer trend toward technology, but also deduce the aspect of "timeliness", highlighting customers who are so concerned about the current service they receive (Kim et al., 2014). The results also show that most customers prefer ICT to traditional services since these services are largely possible by using artificial intelligence and, of course, they make the customer experience easier (Ivanov \& Webster, 2017).

It is also very important to know that there are so many factors which can have a big impact on tourism industry because they can represent one of the reasons why customers choose a specific destination. In this regard, the relevant aspects in terms of choosing the tourism services combine the assets as infrastructure, nature and destination (Beerli \& Martin, 2004). Artificial intelligence 
technology can outperform human performance by providing a large spectrum of data in the shortest time, easily addressing customer needs by providing timely information on the key factors mentioned above. This data comes as a variety of services which the customer can use, such as virtual tours, chatbots, biometric identification and the advantage of translating every existing language.

For further research related to artificial intelligence within tourism industry, we conducted a content analysis using Leximancer software to deduce specific themes and concepts which can highlight the importance and the frequency of the key notions from this field. In line with these themes and concepts, we also had the following objectives:

- Providing a disseminated synopsis of artificial intelligence.

- Exploring the comprehensive theoretical background and development of artificial intelligence research in tourism by focusing on several recent articles.

- Suggesting a future inquiry agenda for tourism researchers.

The themes and concepts found in this content analysis can have certain useful implications in concern with different key subjects and emerging matters. Being an impending and multidisciplinary field, artificial intelligence can contribute with a variety of insights into social sciences and can help us understand even the partnership between humans and new technologies (Pavaloiu et al., 2017). Notably in tourism industry, this type of insights will present perspectives which can help practitioners in times of crisis such as global pandemic or different disasters (Ritchie, 2004). Moreover, they can be a driver for future tourism in terms of trends and challenges for managers when it comes to employees and their willingness to get used with artificial intelligence (Law et al., 2010).

\section{LITERATURE REVIEW}

\subsection{Artificial Intelligence in Tourism Industry}

Artificial intelligence is the game changer that overlays all the new technologies (mobile services, APIs/microservices, Cloud, Internet of Things) for travel, tourism, and transportation. It allows us to finally embrace all of this data that we have not been using because as humans, we don't have the capacity to do it; most companies use almost $10 \%$ of their transactional data from their database. The convergence or the confluence of these key technologies are really going to drive the change in the tourism industry. Nevertheless, it is reported that over the next 5 years we will see more technological change than we saw in the last 100 years.

Artificial intelligence is not just one thing, it is several things: it is natural language, it is voice control, it is all types of analytical information which machine learning can use. With the currently COVID-19 global pandemic, it is absolutely clear that the tourism industry has become more dependent on artificial intelligence and all the new technologies within it. The ongoing global crisis requires from companies all over the world to innovate as much as possible and implement adaptable, responsive, and efficient long-term initiatives and strategies (Gretzel, 2021). Smart technologies as artificial intelligence and robotics have been creating opportunities in the past few years for tourism, travel, and hospitality with or without the pandemic, developing unique business standards, consumer embodiment, and a variety of benefits. The main objective of these technologies highlight encouraging a brand-new approach of traveling experiences for customers.

If we look at it from a customer perspective, artificial intelligence can offer automation and functional experiences. If we look at it from a business perspective, new technologies help in supporting client's engagement, delivering of qualitative service, ensuring the security of the data, and increasing the productivity and reliability of employees (Alt, 2021). If we look at it from a governance perspective, artificial intelligence can really help the management destination to improve its smart techniques of transforming any casual city into a smart city and, therefore, into a smart destination, based on sustainability and the wellbeing of locals and tourists (Xiang, 2021). Artificial intelligence and new 
technologies are expected to have a high positive impact on customers, companies, and locals alike, especially in the field of travel and tourism.

Another regard of highlighted artificial intelligence in tourism industry underlines the utterly contribution for the human achievements in terms of their productivity. Knowing that artificial intelligence is not only about robots taking over our world or even taking over a hotel, studies also emphasize that it is all about enhancing the decisions we make as humans. When we look at what we do across travel and tourism, we can see that there is always a human touch to it, but what artificial intelligence does is to allow employees to take all the benefits of cognitive systems, by providing such better insights for decision-making (Hunter, 2021).

Tourists and employees from tourism field get quite nervous when it comes to artificial intelligence, a critical topic from some perspectives, even if it takes part in our social discourses nowadays, becoming an essential in our life (Tegmark, 2017). Looking at it from a social and working perspective, artificial intelligence changes the skills set because it means that companies no longer need to have analysists plugging data into spreadsheets, running these spreadsheets and doings a lot of analytics. Through new technologies, the employees can have all the insights of the database, structured, organized, so they can take the best decisions. Companies are finally able to look at the business process a little differently because artificial intelligence provides better information (Yen et al., 2021).

Information and Communication Technology systems and tourism industry are based on a lasting history (Gretzel, 2021). Within tourism and travel, key technologies such as recommendation systems, voice control, chatbots, have been designed to offer personalized, context-aware details and locationbased information services along with different customer services provided, such as destination recommendations, itinerary options, hotel recommendations, feedback services (Fesenmaier et al., 2006). The whole diffusion of smartphones and use of internet is challenging the tourism industry in terms of commercial aspects (Al Emadi et al., 2021). What hotels and organizations from tourism industry did in the last few years was to add to their rooms digitalized services as humans use in their own homes, new technologies similar to devices apps as Alexa or Siri. The main reason of doing this emphasized the usefulness of these technologies in different leisure activities (Jing et al., 2021). Moreover, what tourism organizations want is to offer the concept of novel experiences, whether we talk about tourist attractions or the quality of services within a hotel (Tung \& Au, 2018).

The tourism industry has encompassed many features due to the fact that artificial intelligence means not only robots, but also a level of sophistication in terms of services. Furthermore, when it comes to smart tourism, all these new techonologies are integrated in a tangible framework (Gretzel et al.,2015), offering to machine learning the necessary power and independence in the market (Verhoef et al., 2017). As an outcome, the businesses performance is transformed in view of using the artificial intelligence by both employees and customers, being capable of identifying a range of challenges and a lot of opportunities for creating value in the tourism industry (Ivanov et al., 2017).

\subsection{In-room Voice-Based Digital Assistant in Tourism Industry}

Voice control technology is part of so-called ,new normal” tourism and hospitality (Buhalis \& Leung, 2018). Actually, 78\% of tourism companies expect voice-activated devices to become a good alternative for room lights and temperature controls (Oracle, 2017).

Digital assistant for voice control technology started to be a great research topic, especially when it comes to tourism industry, due to the fact that customers still have to get used with it when they reach a hotel room. Voice control technology has been around us in the past few years, allowing humans to have conversations with machine learning in a quite normal way. Hotels started to use digital assistants for voice control to obtain a better approach of what customers want during their vacation, if they have preferences regarding the tourist attractions, if they are concerned about the weather and furthermore how often they love to use the room-service without having to call the reception. In line with this information, there are few hotels which empowered their services with a 
voice-based digital assistant, knowing that they can really achieve a better guests experience. Aloft hotels installed in 2016 Apple Siri in different rooms, based on in-room tablets, while Wynn Resorts from Las Vegas brought Amazon speakers in 4000 rooms (Financial Times, 2018). Intercontinental Hotels Group made a partnership with Baidu in 2018, for using several devices in China. Also, in 2018 was launched Alexa for Hospitality by Amazon, established as a room-hub for improving customers' experience. As for the functionality, advantages and disadvantages, table 1 and figure 1 highlight voice-based digital assistant in terms of hotels and guests' perception (Buhalis \& Moldavska, 2021).

Table 1. Functionality of voice assistants in tourism industry

\begin{tabular}{|c|l|l|}
\hline Themes & \multicolumn{1}{|c|}{ Subthemes } & \multicolumn{1}{|c|}{ Categories } \\
\hline Functionality & Front Desk Requests & Room Service \\
\hline \multirow{5}{*}{} & & Feedback and Complaints \\
& & Housekeeping \\
Check out \\
Facilities Booking \\
Maintenance \\
Transfer \\
\\
\cline { 2 - 3 } & & Wakeup Call \\
\cline { 2 - 3 } & Smart Room Control & Temperature \\
\cline { 2 - 3 } & & Lights \\
& & Curtains \\
& & Media Devices \\
\cline { 2 - 3 } & Emergency Notifications & \\
\cline { 2 - 3 } & Weather Forecast & \\
\cline { 2 - 3 } & Guest Directory & Calendar \\
\cline { 2 - 3 } & Handsfree Calls & Shopping Lists \\
\cline { 2 - 3 } & Personal Accounts Linkage & \\
\cline { 2 - 3 } & & \\
\hline
\end{tabular}

Source: adapted from Buhalis \& Moldavska (2021), p.36

Figure 1.

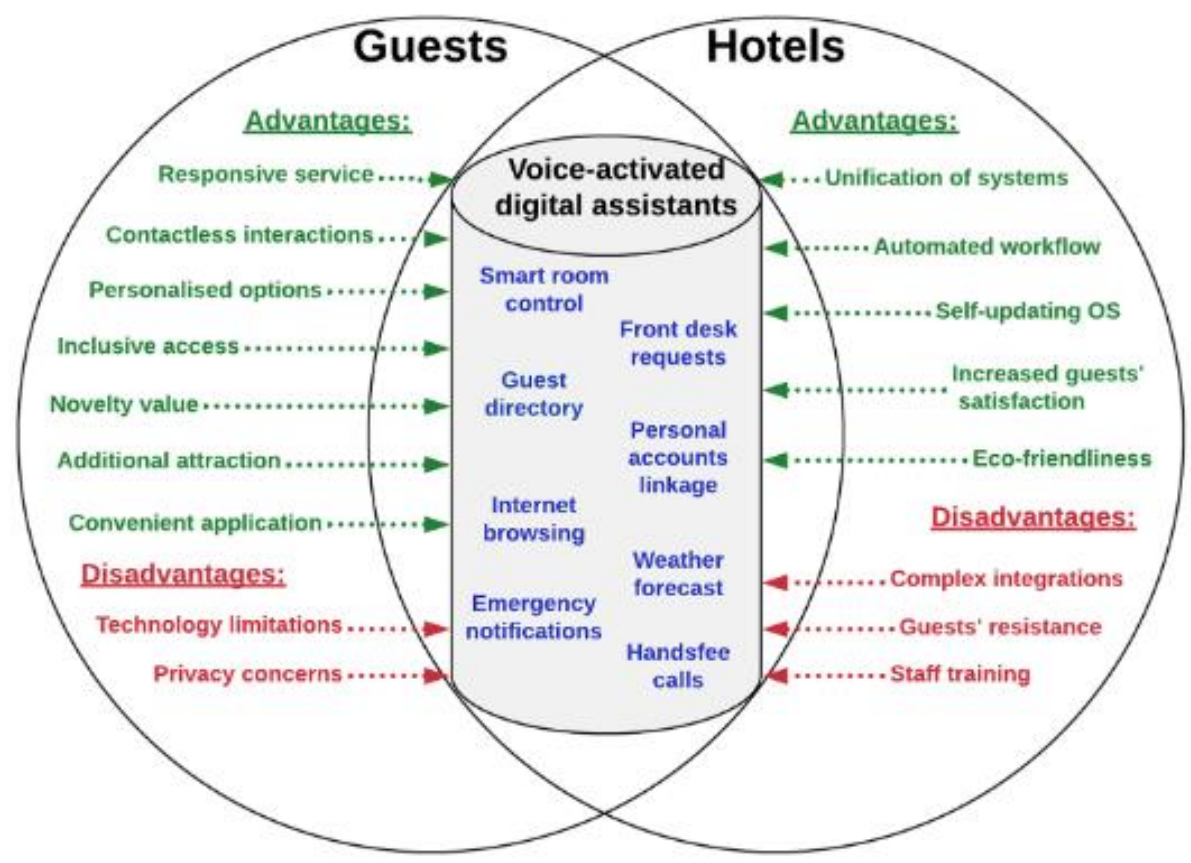

Conceptualisation of speech-based interactions between hotels and guests Source: adapted from Buhalis \& Moldavska (2021), p.41 


\subsection{Facial Recognition in Tourism Industry}

Facial recognition is the most natural form of personal identification and does not limit the action of its user. Facial recognition technology authenticates using biometric data and applies to a variety of areas such as identity verification, access control, unmanned surveillance, and criminal record search in terms of airports sector. Facial recognition does not require any specific action on the part of the user to perform the authentication, and the user does not need to be in contact with the subject. Therefore, it has the advantage of low user resistance, and greater safety is ensured based on different user characteristics.

In facial recognition-based technology, as smartphone performance has advanced, interest in the field to perform certain services using smartphones has increased. Access control systems use a password for security, but when facial recognition is applied to smartphones, it is more secure, allows for more flexible approaches, and no password is needed. With the popularization of smartphones and the tourism industry, this system represents an intangible aspect of the service industry that is going through a period of revolution. Tourists receive support for much of their tourist activities based on convenient mobility and access to the network. A wide range of resources provided by smartphone apps provide tourists with free access to the necessary information anytime, anywhere, and the service provider can support them using the resources provided in mobile device systems. Mobile services offer services in various forms, such as information about the area, finding directions, finding friends, locating a child, location-based advertising, etc. Services that use a map can offer search services such as a specific area, transportation, accommodation, restaurants, and other convenient facilities. Facial recognition is tailored to the travel and tourism industry, also on a large scale. As for the facial recognition in the accommodation units, a very good example is represented by the Marriott International Hotels in Hangzhou, China, which have placed a device inside the hotels through which the tourist scans the identity document, then chooses the facial recognition option, this being the last step of the checkin, after completing all the required information, also online.

As for the whole process of a trip, first of all, tourists must be checked for travel documents in the airport or at any border across the countries. This can take a lot of time, bringing to tourists feelings of frustration and lack of comfort (Patel, 2018). To avoid all of these useless activities, the tourism organizations started to use biometric identification. This is a new technology which allows organizations to get familiar with tourists' face, offering them the opportunity to check-in in a very easy way, without wasting precious time. Furthermore, using this technology also offers the chance to check-in at the airport without having to pass through authorities' control.

\subsection{Virtual Reality in Tourism Industry}

The new techonology using virtual reality realies on using a type of glasses which can present to different customers an artificial environment. It is all about knowing that virtual reality uses a 3D assistance, offering a qualitative way of experiencing extensive length of environment (Guttentag, 2019).

Lately, this technology is often used by companies in the tourism sector, facilitating the opportunity for customers to identify before the trip itself, places and the location of the hotel by using videos. Tourists, from a distance, are usually not aware of the hotel's ambience, the appearance of the rooms, the hotel services, because although companies have details about their hotels written on the website or social media platforms, they don't offer enough photographs and information which can make a clear idea for the customer about how everything looks like. Most of the time, this type of approach leads to ambiguity for customers, this issue being smoothly solved by using VR (Yung \& Khoo-Lattimore, 2019).

The tourism industry uses different applications with virtual reality, offering the chance to have an anticipated tour of the hotel room and also for the entire hotel, experiences of tourist attractions and, 
additionally, the ability to book in advance using virtual platforms. All of the tourists would like to see their next spots in terms of tourist attractions, even before arriving at the destination and the most common thing which they do is to search for other customers feedback with information and photos of the places they are looking for. Because of the use of virtual reality, nowadays, customers have the opportunity to read and see details about everything they need to know regarding their future trip, deciding whether they want or not that destination. These new technologies are perfect even for the customers who don't have the possibility to travel at some point, but they would love to get familiar with specific places and destinations. Merchants offer their clients a simulated vacation to hotels and tourist places, collaborating with both the respective hotels and the tourist attractions (museums, zoo parks and all other recreational places) (Jung et al., 2017).

In order to offer tourists simulated experiences, few organizations such as Atlantis Dubai Hotels and Marriott had partnerships with marketing companies. As for the airlines, the virtual booking interface allows customers a virtual real-time experience of stepping on a virtual airplane, having the possibility to pick an aircraft seat (Navitair Airlines). At the same time, companies such as Emirates Airlines, SriLankan Airlines, Alaska Airlines, British Airways, AirFrance, Garuda Indonesia, use Inflight Entertainment services to offer tourists unique VR experiences in lounges, experiences such as that of virtual theater, series, and documentaries (Skylights, 2021).

Through VR technology, there are other services which can be selected by customers, such as taxi, paying even before taking the cab. Customers are allowed to book tickets on their own and do so many other things, without being in contact with the consulting staff of travel agencies.

\subsection{Chatbots in Tourism Industry}

What a chatbot can do is to have a quick talk with customers through texts or audio methods, using two different ways, depending on the customer choice. The chatbot can have a conversation through text messages or voice messages. The chatbot which uses text messages provides services to customer questions catching up with messages type of communication. The chatbot which uses voice messages provides services to customer questions with a vocal type of communication (Kumar et al., 2016). Chatbots are usually software algorithms for computers that are preprogrammed to answer simple questions raised by customers. The existing algorithms within a chatbot can identify some words in the customers questions that generate a variety of answers to one specific question. After that, the customer can choose between those answers, getting the useful information. Furthermore, a chatbot is available for its customer all over the time, no matter if it is day or night. These meaningful characteristics have led to the replacement of employees with chatbots, or, in most cases, they perform a complementary function to that which the attendant perform. Customers can find this unique service also in the tourism industry. Nowadays, the chatbots are installed even in the car system so that the traveler can drive by himself, without using different guides. Also, when it comes to travel insurance, Asirom, the second largest local insurer in the portfolio of the Austrian group Vienna Insurance Group (VIG), launched in Romania the virtual assistant Clara, the first smart chatbot to issue travel insurance policies.

Each hotel wants its guests to have a unique experience. For the guests it is necessary to have all the information about the facilities within the hotel or the destination. That is how tourism organizations started to use chatbots. The uniqueness of the services is a very important component that tourism industry must implement. In particular, the voice-based chatbot provides its customers with a high-level unique digital service. The customer can choose between ordering room-service, housekeeping, taxi, destination and hotel facilities, scheduling meetings and a range of tasks, etc. (Gajdos \& Marcis, 2019).

In conclusion, it can be considered as a digital assistant to the traveler. Chatbots also keep the whole travelers data which can be used as a suggestion for activities at the destination. The chatbots which use voice messages are specifically designed to increase the hospitality experience, which can improve the whole traveller experience. Hotels that use chatbots include the following: Marriott 
Hotels (Facebook bot), Hyatt Hotels (ChatBotlr), GRT Hotels (GReaTa chatbot), Hotel Casanova Venezia (Hoperator), The Cosmopolitan of Las Vegas (Rose - VIP host), Accor Hotels (Mercure Bot), Four Seasons Hotels (Four Seasons Chat).

\subsection{Robots and IoT in Tourism Industry}

Another kind of artificial intelligence is highlighted in the use of robots in the tourism Industry. Robots use a new technology called the Internet of Things which offers the opportunity to turn off the TV if the customer wants, turning off and on the lights in the hotel room. Moreover, the customer can ensure of the checked-in luggages, by being welcomed in the hotel without being in contact with humans, especially during these times. Front desk robots are in the tourism industry trending since few years already, being totally involved in the experience of interacting with guests. Even the room-service is part of their duties just to make sure that the guests don't face any problem during their time at the hotel.

The Westin, Aloft and St. Regis hotels of the Marriott chain were one of those hotels which received attention when it comes to the use of robots. Aloft Hotels was the first hotel brand which started to use new technologies as robots, so at the beginning of In 2014, they brought to the guest a butler robot called ALO or Botlr. ALO can go throughout the entire hotel to provide room-service and to deliver many things to the guests. Furthermore, another hotel from San Jose Silicon Valley thought that it would be useful to adopt a robot. So, Crowne Plaza, introduced to the guests the robot called Dash which secures the hotel rooms with everything necessary in terms of toiletries, different snacks and many other facilities. This robot uses Wi-Fi connection in order to be able to walk along all the ways of the hotel. Before arriving at the guest's door, he is also able to call and announce that he is going to arrive in a short time. As the home cleaning robots use to do, this robot can also return as fast as possible to its charging point at some specific moments of energy loss. Within the world, there is one hotel entire run by the robots. Its name is Hotel Henn na, from Sasebo, a city which is near Nagasaki, in Japan. Every time a tourist is present at the front desk, the robot comes and greets him. After that, the robot asks the guest to use the touchscreen to easily check-in and obtain any other necessary information. Once the check-in is done, the guest can open the door by using biometric identification. Henn na Hotel provides to the guest another robot called Churi San which can control the room lighting and heating, being also capable of offering the outside and many more. Another hotel from New York, called Yotel Hotel, uses a robot on its name Yobot, which is quite different than the other ones. This robot can also pick-up the guests luggage and leave it into the room. In this regard, it allows guests to check-in quickly and have limited contact with hotel staff.

The main purpose of using robots in tourism industry is to give more time to employee to finish their important task and also to save significant amounts of money. If we think about Chicago, there is one hotel called EMC2 hotel which introduce Cleo and Leo, two robots. What is different about these robots is that they are entirely dresses with coattails, having also badges. As any other robot, their main help can be highlighted in some activities such as bringing to guests extra towels, a variety of snack an drinks, and any other useful things. IBM decided to make a partnership in 2016 with Hilton for McLean Hotel of Virginia, creating the robot called Connie. Connie is a substitute of a concierge, informing tourists regarding the destination, attractions, restaurants and any kind of information they need. IBM's Watson super computer powered Connie being as good as it can be "humanized".

Some of the world airports have also chosen to introduce robots to be used as digital assistants, guiding travelers. One of the most important advantages of robots is that they can really improve all the experiences, facilitate the human work by improving the productivity and efficiency in the tourism sector. 


\section{METHODOLOGY}

\subsection{Leximancer content analysis}

Leximancer automatically ,analyses the text documents to identify the high-level concepts, delivering the key ideas and actionable insights we need with powerful models, interactive visualisations and data exports" (Leximancer, n.d.).

We applied a content analysis based on the most relevant articles, customer surveys, web pages and feedback forms to find out the relationship between themes and concepts by identifying them and taking advantage of what the text really says to conduct further research and to understand what are the main words people think about when it comes to artificial intelligence in tourism industry.

To have better insights about how we should start our qualitative research, we chose the computerbased coding within Leximancer, where the computer is using different algorithms to generate what is important for us - the final coding with themes and concepts. Moreover, all the identified themes and concepts are based on the frequency and patterns of co-occurences due to their correlation in the text.

With Leximancer, we managed to deduce the concepts we needed for deepening our approach as they are composed of many words which are connected and the themes which are seen as set of concepts, using the most dominant ones.

\subsection{Results}

Leximancer generated the most frequently concepts from the resources we used, as well as all the most important themes as sets of concepts. Leximancer generated 11 main themes and 98 concepts from the 40 articles and few customers surveys, web pages and feedback forms. The 11 main themes are artificial intelligence, tourism, robots, services, human intelligence, consumers, robots, chatbots, performance, smart technology, cognitive computing (table 2). For every theme, there is a number of hits calculated and also the frequency, where frequency indicates the importances of the themes, and the hits indicate the number of text parts that is matching each concept.

Table 2. Themes and Concepts in Artificial Intelligence in Tourism

\begin{tabular}{|c|c|c|c|c|c|}
\hline & Theme & Hits & Concepts & Hits & Relevance \\
\hline 1 & $\begin{array}{c}\text { Artificial } \\
\text { Intelligence }\end{array}$ & 1055 & $\begin{array}{c}\text { data, research, technology, } \\
\text { development }\end{array}$ & 823 & $100 \%$ \\
\hline 2 & Tourism & 966 & $\begin{array}{l}\text { people, decision, public, } \\
\text { challenges, opportunities }\end{array}$ & 654 & $100 \%$ \\
\hline 3 & Robots & 936 & $\begin{array}{c}\text { hotel, environment, } \\
\text { experiences, emotions, } \\
\text { customers }\end{array}$ & 506 & $57 \%$ \\
\hline 4 & Services & 772 & $\begin{array}{c}\text { social, interaction, role, } \\
\text { industry, companies, results }\end{array}$ & 432 & $49 \%$ \\
\hline 5 & $\begin{array}{l}\text { Cognitive } \\
\text { Computing }\end{array}$ & 628 & $\begin{array}{l}\text { human, impact, potential, } \\
\text { future, work, understand, } \\
\text { signficant }\end{array}$ & 185 & $21 \%$ \\
\hline 6 & Human Intelligence & 654 & $\begin{array}{l}\text { tourists, analysis, travel, } \\
\text { perception, network }\end{array}$ & 152 & $17 \%$ \\
\hline 7 & Chatbots & 437 & $\begin{array}{c}\text { cognitive, tourism, } \\
\text { technologies }\end{array}$ & 115 & $13 \%$ \\
\hline 8 & Hospitality & 367 & $\begin{array}{c}\text { emerging, opportunities, } \\
\text { challenges }\end{array}$ & 202 & $23 \%$ \\
\hline 9 & Performance & 352 & humans, positive, perceived & 63 & $7 \%$ \\
\hline 10 & Smart Technology & 349 & system, management, support & 179 & $20 \%$ \\
\hline 11 & Consumers & 298 & $\begin{array}{c}\text { experiences, interaction, } \\
\text { social, }\end{array}$ & 137 & $15 \%$ \\
\hline
\end{tabular}

Source: Leximancer software 
All of these themes and concepts which have been generated by Leximancer are going to be mapped using corespondence analysis within a concept map. The corespondence analysis is an observational technique which analyzes data as categories, considering a pattern size for every category. Even if it doesn't offer a statistical significance for the relationship, it supports a detailed overview of the connection between categories.

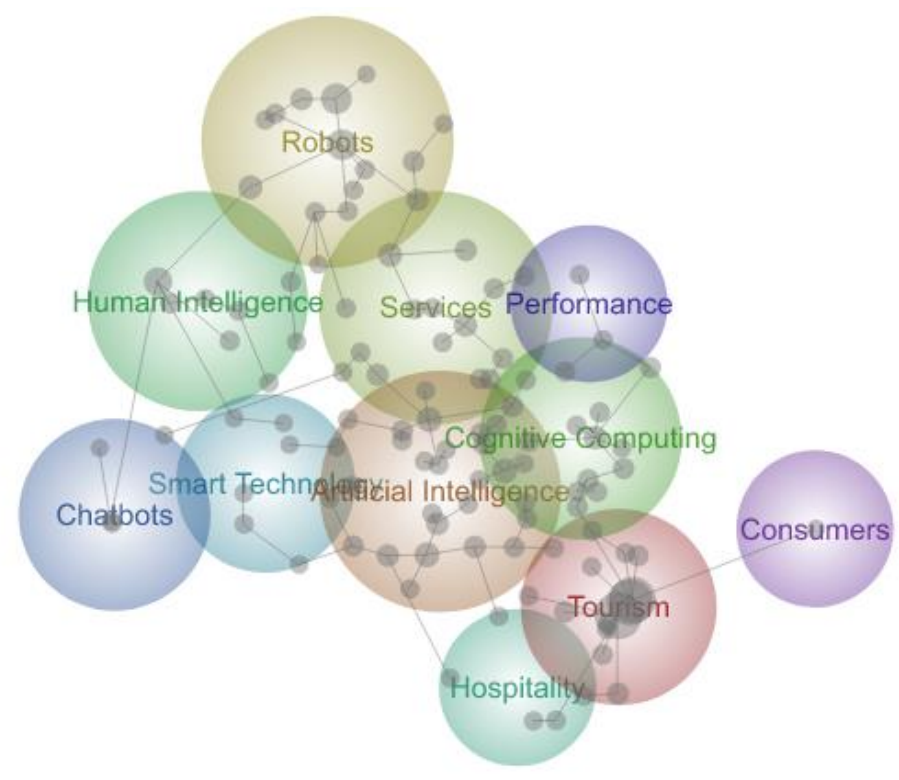

Figure 2. Concept map with themes of artificial intelligence in tourism

Source: Leximancer software

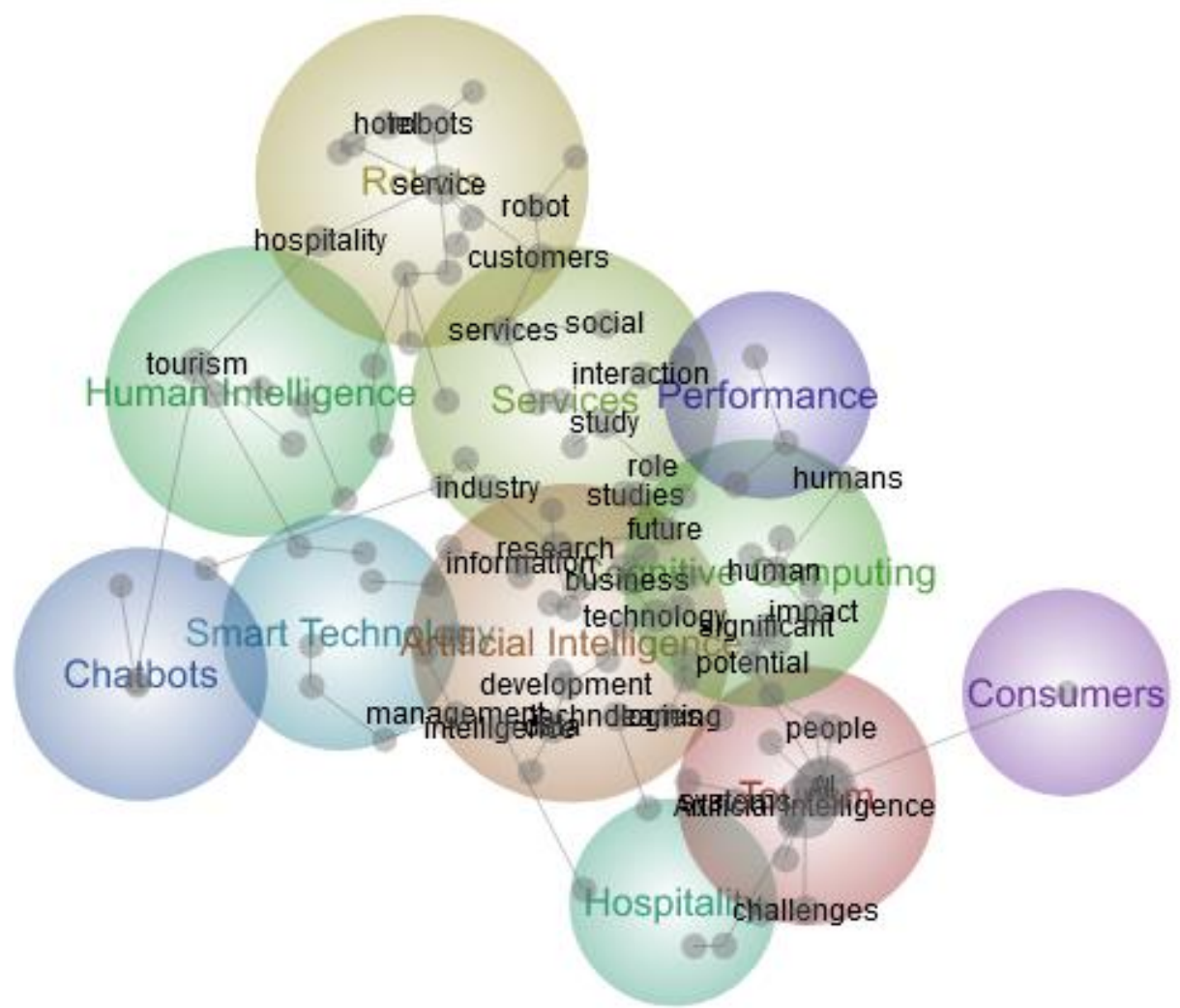

Figure 3. Concept map with concepts of artificial intelligence in tourism Source: Leximancer software 
Table 2 shows the main 11 generated themes, ordered by the number of the content analysis counts. "Count is the number of times a word (concept) appears in the entire corpus (one sentence block)." „Relevance indicates the most frequent occurence, and show proportionality (representative) relative to the other themes" (Leximancer, n.d.). In terms of willing to know the main themes and concepts which should be used in our future research, the counts of themes and concepts suggest that artificial intelligence and tourism have the most counts $(1055,966)$, followed by robots (936), services (772) and cognitive computing (628). Artificial intelligence and tourism appearing so frequently might be due to the main topic of this research and the keywords which we used in order to find the relevant articles and other resources. Mapping the themes and concepts indicates that all of the concepts are distributed along the topic and, furthermore, as we said since the beginning, artificial intelligence isn't only about robots, but it's about several things.

\section{CONCLUSIONS}

Artificial intelligence became step by step one of the most important assets of tourism industry. The new technologies are seen as a big innovation which is continually expanding, causing a high stature for the future tourism sector. The existing studies and statistics show that the travel industry, combined with these new technologies, especially artificial intelligence, will develop with a percentage of $9 \%$ until 2023. This is mainly generated by the fact that the tourism industry is one of the biggest industries in the world, with a significant rising on the global scene. Moreover, the innovative approach of the artificial intelligence, along with all the new technologies, will bring into being a significant outcome. Tourism organizations are nowadays driving different processes by shaping the industry with the help of technologies influence.

According to a Forbes Article, because of the increased global application of artificial intelligence to the travel industry, companies all over the world will create many more jobs. Statistics show once again that starting from 2018, until 2022, the airlines and the tourism sector are going to adopt the idea of retraining, to bring awareness to human resources when it comes to the relevance of new technologies infrastructure. Nearly 58 million new jobs are expected to be created by 2022. Such a planned change could help to address the problem of existing unemployment.

The artificial intelligence concept is both understood as a powerful weapon and a new way of doing things better within the companies. The present paper aimed to challenge new future studies regarding the idea of artificial intelligence and its implementation in the context of industrial tourism. Further studies will clarify the complexity that could arise for tourism industry companies because of the usage of new technologies and artificial intelligence, although many industry experts are suspicious about artificial intelligence, even Stephen Hawking. A holistic assessment should therefore be carried out in case of thinking about the new technologies as if only this would be artificial intelligence itself.

Another point of view which must be considered is that artificial intelligence linked to robots can have a big impact of human resources who believe that, at some point, artificial intelligence is all about taking over the world and the jobs. It is therefore necessary to carry out complete studies and research on artificial intelligence within the tourism industry so that the entire engagement of new technologies will be seriously analysed. More research means that humans will be able to understand both negative and positive impact of new technologies on the tourism industry, companies and, the most important, travellers.

\section{REFERENCES}

Al Emadi, N., Thirumuruganathan, S., Robillos, D. R. \& Jansen, B. J. (2021). Will you buy it now?: Predicting passengers that purchase premium promotions using the PAX model. Journal of Smart Tourism, 1(1), 53-64. 
Alt, R. (2021). Digital transformation in the restaurant industry: Current developments and implications. Journal of Smart Tourism, 1(1), 69-74.

Anurag. (2018). 4 Emerging Trends of Artificial Intelligence in Travel. Retriever October 26, 2021, from https://www.newgenapps.com/blogs/artificial-intelligence-in-travel-emerging-trends/

Beerli, A. \& Martin, J. D. (2004). Factors influencing destination image. Annals of Tourism Research, 31 (3), 657-681.

Bond, S. (2018). Amazon teams with Marriott to put Alexa in hotels. Retriever November 7, 2021, from https://www.ft.com/content/84e8f960-736c-11e8-aa31-31da4279a601

Buhalis, D. \& Leung, R. (2018). Smart hospitality - interconnectivity and interoperability towards an ecosystem. International Journal of Hospitality Management, 71, 41-50.

Buhalis, D. \& Moldavska, I. (2021). In-room Voice-Based AI Digital Assistants Transforming OnSite Hotel Services and Guests' Experiences. Paper presented at ENTER 2021 eTourism Conference.

Casteleiro-Roca, J.-L., Gomez-Gonzalez, J. F., Calvo-Rolle, J. L., Jove, E., Quintian, H., Acosta Martin, J. F. et al. (2018). Prediction of the energy demand of a hotel using an artificial intelligence-based model. Paper presented at The 13th International Conference, HAIS 2018. Oviedo, Spain.

Ferràs, X., Hitchen, E. L., Tarrats-Pons, E. \& Arimany-Serrat, N. (2020). Smart tourism empowered by artificial intelligence: The case of Lanzarote. Journal of Cases on Information Technology, 22(1), 1-13.

Fesenmaier, D. R., Wöber, K. W. \& Werthner, H. (Eds.). (2006). Destination recommendation systems: Behavioral foundations and applications. Philadelphia, USA: Cabi.

Gajdosik, T. \& Marcis, M. (2019). Artificial intelligence tools for smart tourism development. Paper presented at The 4th International Conference on Smart City Applications. Casablanca, Morocco.

González-Rodríguez, M. R., Díaz-Fernández, M. C. \& Pacheco Gómez, C. (2020). Facialexpression recognition: An emergent approach to the measurement of tourist satisfaction through emotions. Telematics and Informatics, 51.

Gretzel, U. (2011). Intelligent systems in tourism: A social science perspective. Annals of Tourism Research, 38(3), 757-779.

Gretzel, U. (2021). Conceptualizing the smart tourism mindset: Fostering Utopian thinking in smart tourism development. Journal of Smart Tourism, 1(1), 3-8.

Gretzel, U., Sigala, M., Xiang, Z. \& Koo, C. (2015). Smart tourism: Foundations and developments. Electronic Markets, 25(3), 179-188.

Guttentag, D. A. (2019). Virtual reality: applications and implications for tourism. Tourism Management, 31 (5), 637-651.

Hunter, W. C. (2021). Cultural representations and experience in tourism: Two forms of mimesis. Journal of Smart Tourism, 1(1), 65-67.

Ivanov, S. \& Webster, C. (2017). Adoption of robots, artificial intelligence and service automation by travel, tourism and hospitality companies - a cost-benefit analysis. Paper presented at International Scientific Conference Contemporary Tourism. Sofia, Bulgaria.

Ivanov, S. H., Webster, C. \& Berezina, K. (2017). Adoption of robots and service automation by tourism and hospitality companies. Revista Turismo \& Desenvolvimento, 27(28), 1501-1517.

Jing, X., Tan, F. \& Zhang, M. (2021). Digital application of intangible cultural heritage from the perspective of cultural ecology. Journal of Smart Tourism, 1(1), 41-52.

Jung, T., Tom Dieck, M. C., Moorhouse, N. \& Tom Dieck, D. (2017). Tourists' experience of virtual reality applications. Paper presented at 2017 IEEE International Conference on Consumer Electronics. Taiwan.

Kazak, A. N., Chetyrbok, P. V. \& Oleinikov, N. N. (2020). Artificial intelligence in the tourism sphere. Paper presented at IOP Conference Series: Earth and Environmental Science. Virtual. 
Kim, T., Kim, M. C., Moon, G. \& Chang, K. (2014). Technology-based self-service and its impact on customer productivity. Services Marketing Quarterly, 35 (3), 255-269.

Kirilenko, A. P., Stepchenkova, S. O., Kim, H. \& Li, X. (2018). Automated sentiment analysis in tourism: Comparison of approaches. Journal of Travel Research, 57(8), 1012-1025.

Kumar, V. M., Keerthana, A., Madhumitha, M., Valliammai, S. \& Vinithasri, V. (2016). Sanative chatbot for health seekers. International Journal of Engineering and Computer Science, 5 (3), $16022-16025$.

Law, R. (2000). Back-propagation learning in improving the accuracy of neural network-based tourism demand forecasting. Tourism Management, 21(4), 331-340.

Law, R., Leung, R. \& Buhalis, D. (2010). An analysis of academic leadership in hospitality and tourism journals. Journal of Hospitality and Tourism Research, 34(4), 455-477.

Leximancer User Guide Release 4.5 (n.d.). In Leximancer. Retrieved November 1, 2021, from https://static1.squarespace.com/static/5e26633cfcf7d67bbd350a7f/t/60682893c386f915f4b05e4 3/1617438916753/Leximancer+User+Guide+4.5.pdf

Oracle Hospitality (n.d.). HOTEL 2025 emerging technologies destined to reshape our business, Retrieved November 5, 2021, from https://www.oracle.com/webfolder/s/delivery_production/docs/FY16h1/doc31/Hotels-2025v5a.pdf

Patel, V. (2018). Airport passenger processing technology: a biometric airport journey (Published master dissertation, Embry-Riddle Aeronautical University, Daytona Beach, Florida). Retrieved from https://commons.erau.edu/edt/385/

Pavaloiu, A., Köse, U. \& Boz, H. (2017). How to apply artificial intelligence in social sciences. Paper presented at IASOS - Congress of International Applied Social Sciences. Uşak, Turkey.

Polson, N., Scott, J. \& Dixon, W. (2018). AIQ: How people and Machines are Smarter Together. New York: St. Martin's Press.

Ritchie, B. W. (2004). Chaos, crises and disasters: A strategic approach to crisis management in the tourism industry. Tourism Management, 25(6), 669-683.

Skylight (n.d.). Signature Cinematic VR Solution. Retrieved November 10, 2021, from https://www.skylights.aero/allosky-vr-in-flight-entertainment-solution

Tegmark, M. (2017). Life 3.0: Being human in the age of artificial intelligence. New York: Knopf.

Topal, I. \& Uçar, M. K. (2018). In tourism, using artificial intelligence forecasting with Tripadvisor data: Year of Turkey in China. Paper presented at International Conference on Artificial Intelligence and Data Processing (IDAP).

Tung, V. W. S., Au, N. (2018). Exploring customer experiences with robotics in hospitality. International Journal of Contemporary Hospitality Management, 30(7), 2680-2697.

Verhoef, P. C., Stephen, A. T., Kannan, P. K., Luo, X. et al. (2017). Consumer connectivity in a complex, technology-enabled, and mobile-oriented world with smart products. Journal of Interactive Marketing, 40, 1-8.

Viglia, G., Furlan, R. \& Ladron-de-Guevara, A. (2014). Please, talk about it! When hotel popularity boosts preferences. International Journal of Hospitality Management, 42, 155-164.

Xiang, Z. (2021). A new platform to support and define an emerging field. Journal of Smart Tourism, 1(1), 1-2.

Yeh, S. H., Wu, A.W., Yu, H. C., Wu, H. C., Kuo, Y. P. \& Chen. P. X. (2021). Public Perception of Artificial Intelligence and Its Connections to the Sustainable Development Goals. Sustainability, 13(16), 9165.

Yung, R. \& Khoo-Lattimore, C. (2019). New realities: a systematic literature review on virtual reality and augmented reality in tourism research. Current Issues in Tourism, 22 (17), 20562081. 
Zheng, W., Liao, Z. \& Lin, Z. (2020). Navigating through the complex transport system: A heuristic approach for city tourism recommendation. Tourism Management, 81, 104162.

Zlatanov, S. \& Popesku, J. (2019). Current applications of artificial intelligence in tourism and hospitality. Paper presented at International Scientific Conference on Information Technology and Data Related Research. Belgrade, Serbia. 